\title{
Study on the Current Situation of Shaanxi Agricultural Insurance and the Development Strategies
}

\author{
Hui Liu \\ Shaanxi Polytechnic Institute, \\ Xianyang 712000 , Shaanxi province
}

\begin{abstract}
Situation combined with policy-related agricultural insurance in Shaanxi and the industry development of Shaanxi rural economy practice, carry out from the Shaanxi agricultural economy development and the agricultural insurance current situation analysis, found the main problems in Shaanxi agricultural insurance, put forward the feasible is given priority to with business management, policy support is complementary to adapt to the rationalization of the Shaanxi agricultural insurance development countermeasure.
\end{abstract}

Keywords- Agricultural Economy; Agricultural Insurance; Insurance Pilot

\section{INTRODUCTION}

Agricultural insurance refers to an economic security for the economic loss caused by natural disasters or accidents in the growth process of crop production and breeding (livestock). Agricultural insurance is necessarily adjusted and developed around the local agricultural structure. Modern agriculture insurance is to help agricultural producers to reduce risk and loss under the condition that peasants' income and agricultural economy are in a state of uncertainty. Agricultural insurance is of profound, great, and realistic significance to the healthy development of agriculture and the fundamental guarantee of the national development.

\section{The role of agricultural insurance}

Agricultural insurance is a product of the agriculture development to some extent. Agriculture undertakes the threat of social risk and economic risk, and this affects the sustainable development of agriculture. China's agricultural risk mechanism is very fragile, and this is caused by many factors, and therefore, a risk management mechanism for transferring the risk and reducing the economic loss is required. Under this situation, the modern agriculture insurance arises. The development of agricultural insurance is of important theoretical significance and far-reaching practical significance to the smooth agricultural reproduction and promoting the sustainable development of agriculture.

\subsection{The effect of agricultural insurance on individual peasants}

Agricultural insurance can provide timely compensation for the insured peasants within the scope of insurance liability once disasters occur. Agricultural insurance can transfer and split risks and protect the peasants' life stability in the form of compensation.

\subsection{The effect of agricultural insurance on economy}

Agricultural insurance can guarantee the sustainability and stability of the agricultural production process. It can make the large and unstable agricultural economic loss converted to the cost of a small, fixed agricultural insurance.

\subsection{The effect of agricultural insurance on the entire national economy}

In China, agriculture is the foundation of the whole national economy, and its fluctuation is an important cause of the floating national economic cycles. Therefore, agricultural insurance can indirectly protect the coordinated development of the entire national economy 
when directly promoting the healthy and stable development of agricultural production and operation activities.

\section{The current situation and problems of Shaanxi's agricultural insurance}

Agricultural insurance is a kind of quasi-public products with positive externalities, and its positive externalities are reflected in two aspects (the consumption or demand of peasants for agricultural insurance; the production or supply of insurance company). This is because supply and consumption are of dual externalities and promote agricultural insurance to feature "insufficient demand and limited supplies". Currently, Shaanxi province's agricultural insurance is restricted by both effective supply and demand.

First, Shaanxi rural areas are wide; the population is large; the production scale is small. As a result, the complexity of the agricultural insurance business and the difficulties of the basic insurance service are caused; grass-roots agriculture and forestry management agencies are still needed for the smooth development of underwriting and settlement of claims. Shaanxi is the province in which agricultural natural disasters frequently occur. Because of the feebleness of the agriculture and the particularity of the production process, the peasants always bear the risks of both nature and market, and their agricultural income is unstable.

How to promote peasants to fully understand the insurance mechanism and the insurance clauses, how to establish a sound grass-root service system, and how to strengthen and introduce new technologies to improve the efficiency of insurance and reduce the risk of moral hazards have been important issues necessary for China's agricultural insurance management personnel to think deeply and solve.

Second, the types of agricultural insurance in Shaanxi province are few - the current agricultural insurance cannot satisfy the development of the rural areas in terms of both the number of insurance companies and the types of the agricultural insurance. The development of agricultural insurance doesn't adapt to the rural economic development and the peasants' needs; insurance design products also can't meet the diversified, multi-level needs presented by the rural economy for agricultural insurance.

Third, the agricultural insurance operation model is simple and also the operators are few in Shaanxi province; the insurance services of commercial insurance companies are mainly applied. The probability to bear the risks is higher in agricultural insurance, and also huge losses and wide coverage are common. Therefore, the loss ratio of insurance company is relatively high, and the insurance company specialized in rural insurance business may be in a state of loss for a long time and also can't timely implement rural insurance business in some backward areas; the insurance business in some areas may shrink. Meanwhile, the agricultural insurance market operation efficiency is lower, and the market failure occurs.

Fourth, there are many problems in the agriculture insurance of Shaanxi province. For example, the insurance company standard rates are greatly higher than the actual delivery capability of peasants; the payment capability of peasants is weak; agricultural insurance loss ratio is higher; peasants are unable to cover insurance; insurance companies are reluctant to accept insurance. As a result, the agricultural insurance business is in a contracting state year after year in the province and this has become one of the bottlenecks to restricting the rural insurance business.

\section{Analysis on the strategies for the development of Shaanxi's agricultural insurance}

With the rapid development and adjustment of Shaanxi's agricultural economy, it is necessary for the government to make the best use of the circumstances and have the courage to bring 
forth new ideas according to the problems of the agricultural insurance development. Thus, experience is accumulated in practice, and a new way centered on business and aided by policy is explored.

\subsection{Gradually training the peasants' awareness of the agricultural insurance market and solving the reproduction and life problems through agricultural insurance}

Shaanxi is one of Chinese provinces in which agricultural disasters are frequent. The main natural disasters include hail, drought, storm and flood; the agricultural economic loss every year is up to hundreds of millions of dollars. Many peasants are not aware of agricultural insurance, and they generally think insurance is a superfluous thing. However, the agricultural economic loss can't get enough compensation from agricultural insurance once disasters occur, so that the recovery and development of the local agriculture are affected. Therefore, it is very important to help peasants build up a strong sense of risk aversion.

\subsection{Agricultural insurance is an important part of the governmental agricultural policy}

The government of Shaanxi province needs to implement the institutional measures orderly for the agricultural insurance operation model. Government's financial support is the basic guarantee of the development of the agricultural insurance. At present, in the financial support of China for the agricultural insurance development, subsidies to premium, tax preference, management fee subsidies, and the establishment of catastrophe risk are necessarily used as four major ways.

In 2003, policy agricultural insurance pilot project was raised by the state's government. By 2008 , the pilot was expanded to 16 provinces and Xinjiang Production and Construction Corps. At present, the system of "government subsidies + insurance company + peasant household" is adopted in the actual execution of China's policy-based agriculture insurance, but the commercial operation of the insurance companies remains to be primary. The high risk, spatial dispersion, and seasonal characteristics of agricultural production have resulted in the high cost of agricultural risk management and also decide the insurance companies to maintain the normal operation with high rate.

This year, the policy-based agricultural insurance pilot will be further promoted in Shaanxi province to realize a complete coverage of the public welfare forest insurance. According to the Plan for the Implementation of Shaanxi's Policy-based Agricultural Insurance Pilot in 2015 made by the Financial Department and Insurance Regulatory Bureau of Shaanxi province, Shaanxi's policy-based agricultural insurance pilot includes 17 varieties such as sows, cows, wheat, corn, walnut, and jujube and involves 95 counties of the province.

\subsection{Positively changing the business strategy of commercial insurance companies for agricultural insurance products}

Commercial insurance companies need to positively bring forth new ideas into the agricultural insurance products, services and sales channels and gradually expand the coverage of insurance products. At the same time, the underwriting product projects and insured coverage are appropriately broadened. Insurance companies need to secure the needs according to the rural urbanization and agricultural industrialization and provide marketable products based on the peasants' payment capability in the business of agricultural insurance. Concerning about the needs of the traditional planting and breeding industries, concentrated insurance products are timely offered, so as to protect the interests of the mass peasants once agricultural disasters occur. In property insurance such as houses, machinery and poultry, the policy of "operating the insurance based on premium" is implemented. 
The key areas such as high-tech planting and breeding industries feature high cost and high yield, and therefore, the current traditional model is necessarily broken to improve the technology contents of agricultural insurance and the innovation of insurance products.

\subsection{Establishing a sound agricultural insurance service system and improving the level of grass-root services}

In all pilot areas, the support for the construction of agricultural insurance service network is necessarily enlarged; the agricultural insurance agency services are helped to provide better grass-root services. The agricultural insurance agencies need to set up a full-time working group and undertake the countryside services, so that peasants get familiar with the policies, terms and business flow of the agricultural insurance; insurance certificate is timely issued once the insurance premiums are collected; the related work such as survey, loss assessment, and the settlement of claims is done once loss occurs, aiming to reduce the loss caused by peasants and let them gain economic compensation in time.

Agricultural insurance agency can entrust grass-roots agricultural technology institutions to cooperatively deal with the agricultural insurance business. Insurance institutions must sign a written contract with the entrusted institutions to handle the agricultural insurance business, so as to clearly define the rights and obligations of both sides, negotiate the cost and payment, and provide business training and guidance for agricultural insurance institutions. Agricultural insurance agencies assist to deal with the payment of agricultural insurance business according to the rules stipulated in Management Methods for Shaanxi Policy-based Agricultural Insurance. By March 2015, the agricultural insurance agencies in Shaanxi had set up 180 township branches and 1393 rural insurance service offices, and employed 14,000 insurance service personnel, thus promoting the capability of the grass-root agricultural insurance service to effectively improve.

To better promote the policy-based agricultural insurance, agricultural catastrophe insurance emergency fund system was established in the province; management methods for agricultural catastrophe emergency funds were made, for further improving the agricultural catastrophe risk diversification system and regulating the agricultural catastrophe insurance reserves provision, use and management.

A sound insurance market has to incorporate four elements: subject element, object element, capital element, and production element. The development of the insurance market not only needs mature underwriters and rational applicants, in order to promote the development of agricultural insurance. Therefore, to develop the agricultural insurance market, great efforts are necessary in terms of underwriters and applicants.

\section{Conclusion}

To develop the modern agriculture, the key lies in science and technology and finance. In recent years, the market economy is in the rapid development, and finance is becoming a major factor restricting the development of agriculture. In this process, insurance plays many functions such as reducing the economic loss, the accommodation of funds, and social management; insurance is also one of the basic means of risk management and plays a vital role in protecting the agricultural production stability.

\section{References}

[1] Xinhua Yang, Jianfeng Zhu. Domestic Agricultural Insurance Subsidies Research Review [J]. Journal of Fuyang Normal College Journal (Social Science Edition), 2010, 03.

[2] Gang Wu. The International Comparison on Agricultural insurance Development and 
Inspiration and Reference [J]. Journal of Business Research, 2001, 02.

[3] Yonghui Wu, Baosheng Zhou. Difficulties and Development Ways of China's Agricultural Insurance System Construction [J]. Journal of Hefei Normal University, 2008, 02.

[4] Junsheng Zhu, Guozhu Tuo. The Development of China's Agricultural
Insurance from Public-private Partnership Perspective $[\mathrm{J}]$. Journal of Insurance Research, 2009, 03.

[5] Xuzhong Wu. Several Ideas about the Current China's "Three Rural Issues" [J]. Journal of Hefei Normal University, 2011, 05 . 